\title{
Letters
}

\section{Central pattern generator}

I have read the recent article of $\mathrm{Dr}$ Illis ${ }^{1}$ with great interest. I agree with the argument that the increase in EMG activity observed during the locomotor training in paraplegic patients ${ }^{2}$ is no absolute proof for training effect, because we did not have an adequate control group. Nevertheless there are other observations supporting the view of a training effect, discussed elsewhere ${ }^{3}$.

However, the conclusion drawn by Dr Illis that 'These studies do not absolutely prove the existence of a central pattern generator in man ...' appears to be based on a wrong fact. Our assumption of a spinal pattern generator in man was not based on the increase in EMG-activity but on a fact that a coordinated, complex EMG pattern in the leg muscles could be induced in complete paraplegic patients.

The author doubts the novelty and significance of our results. However in our papers on the locomotor training in paraplegic patients ${ }^{2,3}$ leg muscle EMG activity was systematically recorded in all patients during the training period, the EMG was quantified and further analysed. Only by such a methodological approach changes can be assessed in the activity of the spinal pattern generator underlying locomotion. Such an approach was not applied in any one of the papers cited by the author ${ }^{1}$ except in Dietz et l. $^{2}$ The significant changes in the EMG activity pattern observed ${ }^{2,3}$ paralleled the ability of the incomplete and complete paraplegic patients to overtake body load during locomotion.

This aspect seems to be of importance as a locomotor improvement might also be based on changes in the muscular-tendon systems.

To our knowledge this was the first report on this matter. Certainly, such an observation was not already reported by Wernig and Muller ${ }^{4}$ as suggested in the paper of Dr Illis.

Prof V. Dietz Schweizerisches Paraplegikerzentrum University of Balgrist 8008 Zurich

Forschstrasse 340

Switzerland

1 Illis LS. Is there a central pattern generator in man? Paraplegia 1995; 33: 239-240.

2 Dietz V, Colombo G, Jensen L. Locomotor activity in spinal man. Lancet 1994; 344: 1260-1263.

3 Dietz V, Colombo G, Jensen L, Baumgartner L. Locomotor capacity of spinal cord in paraplegic patients. Ann Neurol 1995; 37 (in press).

4 Wernig A, Müller S. Laufband locomotion activity with body weight support improved walking in persons with severe spinal cord injuries. Paraplegia 1992; 30: 229-238.

\section{Reply from Dr LS Illis}

Professor Dietz is correct in saying that Wernig and Muller $(1992)^{4}$ reported on incomplete spinal injured patients. However, the importance of proving a central pattern generator for locomotion in Man is such that all possibilities must be explored or at least considered and this must include a discussion on the total elimination of any supraspinal influence. If Professor Dietz is satisfied that this was the case in his patients, then his findings are indeed of considerable import since this raises the possibility that the loss of supraspinal control may be overcome by the use of appropriate afferent stimulation, training and perhaps with the use of intrathecal drug delivery systems.

I believe that the first demonstration of a probable central pattern generator in Man with a complete spinal cord section was by Bussel et $a l^{1}$ who studied a patient with a complete spinal cord section and who exhibited rhythmic contractions.

Dr LS Illis

Wessex Nuffield Hospital

Winchester Road

Chandlers Ford

Hants SO53 2DW, UK

1 Bussel B et al. Myoclonus in a patient with a spinal cord transection. Possible involvement of spinal stepping generator. Brain 1988; 111: 1235-1245.

\section{Energy cost of walking}

Regarding the interesting and ambitious paper by Lotta et $a l^{1}$ who have a worthwhile experience and make some important and relevant observations, there is, however, an anomaly between the reporting of experience and the tabular information. The text states that 'The HGO patients could only walk with a walker...' (page 611), whereas the Table on page 612 seems to indicate they walked with crutches.

Research elsewhere suggests that the tabular information is correct. Whittle and Cochrane (1989) ${ }^{5}$ showed that more patients in a cross-over trial used crutches with the ParaWalker than they did in the RGO, Banta et al $(1991)^{1}$ and Bowker et al $(1992)^{2}$ both showed the ParaWalker to cost less energy in crutches than the RGO.

Perhaps the most important measure of success is patient compliance. Two separate studies of thoracic lesion traumatic paraplegic patients using the ParaWalker with crutches (Moore and Stallard, 1991; ${ }^{4}$ Stallard et al., $1995)^{5}$ have shown very similar compliance rates $64 \%$ and $60 \%$ with average usage period of 34.4 months and 38 months respectively. Spina Bifida patients with lesions at Ll or above who have become adult users have shown compliance of $59.4 \%$ with an average 12 year usage period.

The small but important flaw in the Lotta et al paper ${ }^{3}$ should not detract from its overall impact. It is 
appropriate to make comparison and the main message that these systems can be successful but do require supply through a fully trained team providing ongoing support mirrors the experience of those who have produced satisfactory research results elsewhere.

John Stallard B Tech, C Eng, FI Mech E, FBES, FBIST(Hon) Technical Director Orthotic Research \& Locomotor Assessment Unit Robert Jones \& Agnes Hunt Orthopaedic Hospital Oswestry SY10 7AG, UK

1 Banta JV, Bell KJ, Muik EA, Fezio. ParaWalker: Energy cost of walking. Eur. J. Pediatric Surg. 1991; 1: Suppl 1: 7-10.

2 Bowker P, Messenger N, Ogilvie C, Rowley D. The energetics of paraplegia walking. Journal of Biomedical Engineering 1992; 14: 344-350.

3 Lotta S, et al. Paraplegia 1994; 32: 608-615.

4 Moore P, Stallard J. A Clinical review of adult paraplegic patients with complete lesions using the ORLAU ParaWalker. Paraplegia 1991; 29: 191-196.

5 Stallard J, Major RE. The use of the ORLAU ParaWalker by adult myelomeningocoele patients: a seven year retrospective study. To be presented at 39th Annual Scientific Meeting of the Society for Research into Hydrocephalus and Spina Bifida, Bristol 5-8 July 1995.

6 Whittle MW, Cochrane GM. A comparative evaluation of the hip guidance orthosis (HGO) and the reciprocating gait orthosis (RGO). Health Equipment Information, London: National Health Service Procurement Directorate, 1989, 192.

\section{Reply from Dr L Tesio MD}

We are grateful to Mr Stallard for his keen analysis of our paper evidencing a contradiction between the text and one table. We confirm that our four HGO patients could only walk with a walker. This has been a typing mistake for which we apologise to the editor and to readers.

We appreciated very much his opinion that, despite this flaw, the paper is not devoid of an overall impact. Perhaps the main aim of our epidemiologic study was a claim for more attention to the outcome as seen from patient's perspective rather than from a biomechanical standpoint. $\mathrm{Mr}$ Stallard is an eminent scientist in the field of gait engineering and we fully appreciate his statement that 'perhaps the most important measure of success is patient compliance'.

Dr Luigi Tesio

Department of Research Functional Assessment and Quality Assurance in Rehabilitation Fondazione Clinica de Lavoro via Clefi 9, 20146 Milan, Italy 